\title{
Erratum
}

\section{Use of punctuation for pausing: Oral readings by German radio homilists}

\author{
Daniel C. O'Connell ${ }^{1, *}$ and Sabine H. Kowal' \\ 1 Loyola University of Chicago, 6525 North Sheridan Road, Chicago, IL. 60626, USA \\ 2 Technische Universität Berlin, Straße des 17. Juni 135, D-1000 Berlin 12
}

Psychol Res (1986) 48:93-98

Table 1 on page 94 was reproduced incorrectly. Every line in the table should begin with a period, which indicates that, according to all authors quoted, the period should receive the longest relative pause duration. The correct form of the table is given below:

Table 1. Sample hypotheses regarding relative duration of pauses at various types of punctuation and at unpunctuated between-word positions (null)

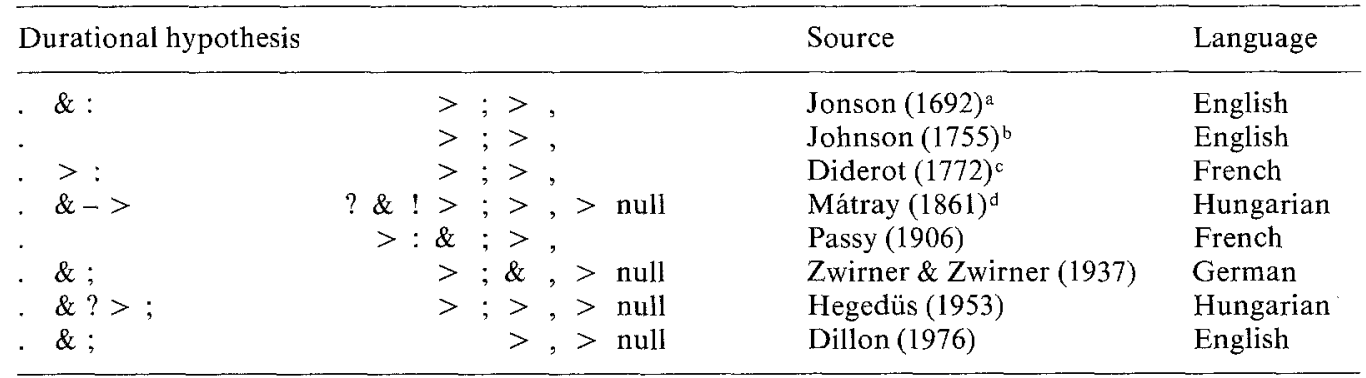

a Cited in Ong (1944, p. 356)

b Cited in Honan (1960, p. 94)

c Cited in Védénina (1973, p. 33)

d Cited in Hegedüs (1953, p. 2) 